Soares, A.S.; Azevedo, F.F. Consumo e conservação no Ecoturismo das UCs Área de Proteção Ambiental Jenipabu e Reserva de Desenvolvimento Sustentável Estadual Ponta do Tubarão (RN): a percepção dos atores que nelas atuam. Anais do VIII Congresso Nacional de Ecoturismo e do IV Encontro Interdisciplinar de Ecoturismo em Unidades de Conservação. Revista Brasileira de Ecoturismo, São Paulo, v.4, n.4, 2011, p. 533.

\title{
CONSUMO E CONSERVAÇ̃̃O NO ECOTURISMO DAS UCs ÁREA DE PROTEÇ̃̃O AMBIENTAL JENIPABU E RESERVA DE DESENVOLVIMENTO SUSTENTÁVEL ESTADUAL PONTA DO TUBARÃO (RN): A PERCEPÇÃO DOS ATORES QUE NELAS ATUAM
}

\section{Artemísia dos Santos Soares*, Francisco Fransualdo de Azevedo**}

*Instituto Federal de Educação Ciência e Tecnologia do Rio Grande do Norte, **Universidade Federal do Rio Grande do Norte

E-mails: artemisiasoares@yahoo.com.br, ffazevedo@gmail.com

$\mathrm{Na}$ contemporaneidade o ecoturismo tem apresentado forte crescimento no mercado turístico mundial, acompanhando e fomentando um contexto de discussões globais sobre os problemas e as demandas ambientais, bem como evidenciando a necessidade de um aprofundamento científico através de um debate crítico sobre o imperativo do consumo vivido atualmente, questionando-se as dinâmicas de consumo e conservação que permeiam a prática ecoturística. Este estudo se dedica a analisar a percepção dos agentes que atuam no ecoturismo das Unidades de Conservação (UCs) de uso sustentável Area de Proteção Ambiental Jenipabu (APAJ) e Reserva de Desenvolvimento Sustentável Estadual Ponta do Tubarão (RDSEPT). A pesquisa buscou averiguar as relações entre conservação e consumo e suas influências no ecoturismo realizado nas UCs de uso sustentável selecionadas para este estudo. Para tanto se teve como percurso metodológico uma abordagem qualitativa sob uma perspectiva crítica, baseada em pesquisa bibliográfica e documental e realização de entrevistas semi-estruturadas com três grupos de agentes, a saber: gestores/técnicos, comunidade e ecoturistas envolvidos com o ecoturismo nas UCs selecionadas. O estudo foi realizado utilizando-se duas unidades de análise principais (consumo e conservação) subdivididas em doze categorias. Para a fixação das unidades de análise e categorias, tomou-se como referência autores que realizam crítica à sociedade do consumo e apresentam as principais características do meio técnico-científicoinformacional predominante, tais como Santos $(1987 ; 1988 ; 1994 ; 2001 ; 2006)$, Guerreiro Ramos (1989) e A. B. Rodrigues (1996; 2003); e autores que tratam histórica e cientificamente acerca da relevância do conceito de conservação existente na gênese e no discurso do ecoturismo, descrevendo também suas características essenciais, como Diegues (1998; 2000), A. B. Rodrigues (2001), Pires (2002) e Neiman e Rabinovici (2010) Os principais resultados revelam que o uso mercadológico do prefixo "eco" tem atuado como uma nova roupagem para o que na realidade ainda se revela antigo, ou seja, usa-se a conservação como justificativa para mais um novo tipo de consumo. Os resultados também evidenciam que apesar da coexistência de intencionalidades mercantis e simbólicas em ambas UCs, é possível observar a predominância de características fundantes da sociedade do consumo em massa no processo de criação e nas atividades produtivas da APAJ, enquanto na RDSEPT nota-se em certa medida a predominância das características conservacionistas apregoadas pelo ecoturismo. Isso se constata também na percepção dos atores entrevistados, os quais estão envolvidos com o ecoturismo nas UCs pesquisadas. Ou seja, as diferenças presentes no processo de criação também estão presentes no cotidiano e discurso dos envolvidos. Pode-se inferir, portanto, que o turismo realizado na APAJ não pode ser denominado de ecoturismo, enquanto as práticas observadas na RDSEPT evidenciam um alinhamento com as diretrizes do ecoturismo.

Palavras-chave: Ecoturismo; Consumo; Conservação. 